\title{
A URBANIZAÇÃO CRÍTICA NA METRÓPOLE DE SÃO PAULO A PARTIR DE FUNDAMENTOS DA GEOGRAFIA URBANA
}

Amélia Luisa Damiani Profa. do Departamento de Geografia, FFLCH, USP ameluisa@usp.br

\section{Resumo}

As metamorfoses de concepções da geografia urbana havíam assumido o tom da agitação dos conteúdos da realidade urbana. Este contexto nos aproxima de uma atualização da bibliografia geográfica, sem simplificações extremas, nem o desdenhar de todas as suas perspectivas. Pierre George nos dá um exemplo extraordinário da extensão deste conhecimento, precipitadamente, tornado obsoleto.

Palavras-chave: Concepções da geografía urbana Urbanização empírica Urbanização crítica.

\begin{abstract}
The metamorphoses of concepts of urban geography had assumed the tone of a agitation of urban reality. We are about to update the geographical literature, without extreme simplifications, or disdain all their perspectives. Pierre George gives us an extraordinary example of the extent of that knowledge, abruptly become obsolete.
\end{abstract}

Key Words: Concepts of urban geography Empirical Urbanization Critical Urbanization.

\section{$\circ \bigcirc \circ$}

\section{METAMORFOSES DE CONCEPÇÕES DA GEOGRAFIA URBANA}

É extraordinário examinar o livro de Pierre GEORGE, Geografia Urbana ${ }^{1}$, a luz da realidade da urbanização de nossos tempos. Trata-se de encontrar a potência da observação dos fenômenos urbanos, nos anos 1950-60, e avaliar como o corpo conceitual da Geografia, deste período, lidava com fenômenos tão mutáveis, como aqueles que envolvem o urbano.

O autor buscou dentro da Geografia uma concepção de totalidade dos processos geográficos, que atravessavam as cidades no mundo, nos anos 1960. O livro data de 1961. Contudo, já em 1952, ele escrevia sobre o tema, desse ponto de vista: o de uma geografia geral sobre o urbano no mundo, sugerindo tipos de cidades e os condicionantes de seu crescimento urbano, de sua repartição desigual no mundo, em estudos comparativos ${ }^{2}$.

Os instrumentos analíticos em voga, à época, conceituavam a cidade como um organismo urbano. Essa concepção orgânica atravessa a Geografia alemã e a francesa, resvala na influência das ciências naturais e biológicas no interior das ciências humanas, o que foi conceituado como positivismo na Geografia, e é possível incluí-la nos fundamentos do pensamento sobre o urbano de Pierre GEORGE. Mas tais instrumentos analíticos já apresentavam sinais evidentes de sua ruptura e limite. Nesse livro, as cidades são conceituadas como organismos urbanos e se agrega à conceituação a idéia de aglomeração urbana: a cidade e suas aglomerações urbanas, afinal, sintetizam as noções de fundamento. A rigor, essa composição já é contraditória e sustenta uma situação de impasse, inclusive conceitual: a negação da cidade como organismo urbano coerente e solidário em seus elementos constitutivos. A noção de aglomeração urbana já expressa à iminente contradição. Leituras recentes sobre o autor demonstram a potência crítica de seus escritos sobre o urbano, vislumbrando a crise urbana. 
Podemos estabelecer a seguinte tese: o livro apresenta um descompasso entre as observações empíricas do processo de urbanização e o acervo conceitual disponível; ao mesmo tempo, de modo rico e complexo, anunciava novas concepções, confirmadas pela realidade urbana atual. O movimento de interpretação do livro sugerido, portanto, é informado pelas novas abordagens e fenômenos urbanos. Sua leitura compôs sua primeira e sua segunda partes, simultaneamente, pois a segunda elucida conceitualmente o trajeto empírico da primeira.

Numa linha de continuidade, que tenta decifrar o processo de urbanização, como pensado por Pierre GEORGE, à luz desta primeira aproximação, que é a população, tem-se o seguinte movimento: da urbanização difusa, de crescimento gradual e constante, à urbanização empírica, de crescimento abrupto e acelerado.

No movimento do texto, a concepção ganha mais plasticidade, absorvendo o tratamento do fenômeno urbano em sua complexidade, embora, conceitualmente, ainda haja hiatos: a cidade e suas aglomerações urbanas - a cidade não vem sozinha, mas sempre acompanhada desse adendo "aglomerações urbanas", formando o que o autor designa como conjunto urbano.

Embora o tratamento das cidades inclua os bairros, como modo de organização do espaço, aparecem os termos analíticos da urbanização empírica, contraditória a essa organicidade, em princípio designadora do fenômeno: zonas periféricas, áreas suburbanas, guetos, segregação urbana, habitats espontâneos, como áreas incluindo populações "não integradas". As peculiaridades dos chamados países subdesenvolvidos seriam reveladoras dessa realidade instável.

O fenômeno urbano é tratado em extensão: vários modos de crescimento, cujo teor maior é a aceleração do processo de concentração de população nas cidades; que, por sua vez, define mudanças intensivas das cidades. As metamorfoses sócio-culturais do urbano equivalem às perdas de gêneros de vida, próprios de coletividades singulares, de identidades perenes e à afirmação de identidades regionais e nacionais provisórias, como o caso de guetos; o sentido é do esgotamento dessas identidades concretas.

A perspectiva da cidade como organismo urbano é também a compreensão da cidade como obra humana, aquela que reflete e, ao mesmo tempo, humaniza o homem. Nesta literatura geográfica sobre a cidade antevê-se um embate surdo, não refletido completamente, ambíguo teoricamente, entre a humanização e a desumanização, expresso na manutenção da idéia da cidade como organismo urbano. Essa ambigüidade conceitual também é aquela da relação não plenamente resolvida entre o imediato e o mediato; a dificuldade da compreensão da presença constitutiva da abstração nas relações sociais modernas. Por outro lado, o espaço guarda outros tempos, incluindo os da imediaticidade das relações sociais. Os próprios princípios de tratamento da população: por idade, sexo; equivalendo a diferenças primárias, ainda mantêm esse caráter antropológico.

Mas, a voracidade do processo urbano, da urbanização, recebe, nesse método geográfico, um impulso necessário e considerável, inclusive, pondo em questão, de alguma forma, o conceito de organismo urbano, no caso do estudo das cidades. Estaríamos resvalando algo relativo à noção de medida - quando a quantidade deixa de ser estritamente um elemento indiferente e passa a ser ativo, impulsionando a dialética entre quantidade e qualidade ${ }^{3}$.

O reconhecimento é o da universalidade e o da aceleração do crescimento dos grandes aglomerados urbanos (de milhares a milhões de habitantes); ele sugeriria tipos de cidades. Vislumbra-se a necessidade de comparação das cidades no mundo. Mede-se a extensão e intensidade da ocupação territorial urbana, que, ao mesmo tempo, sugere um tratamento em espectro, de situações globais a escalas intra-urbanas, considerando as transformações do aspecto físico urbano e da vida cotidiana no urbano, por exemplo, o ritmo de crescimento das periferias, com superpovoamento crítico (densidade maior de ocupação por cômodo da casa; afluxo maior de migrantes homens jovens e jovens casais; até zonas suburbanas, enquanto 
consumidoras de homens, "pois nelas a morte sobrepuja a vida”, quando o emprego é instável). A coroa suburbana apresenta-se como frente pioneira e de colonização da urbanização. Essa leitura manifesta sua atualidade inconteste. $\mathrm{O}$ urbano espelha e reproduz o aspecto crítico da economia capitalista: no limite, "o enorme contraste de renda entre classes dirigentes e proprietárias, e a massa da população sem poder aquisitivo, que vive, no sentido próprio do termo o dia a dia" ${ }^{4}$.

De um lado, a cidade configura uma unidade demográfica; de outro, as coletividades geográficas inclusive os bairros — são substituídas pelas relações sócio-profissionais. A superação da tradição de se pensar o meio geográfico e suas diferenciações, através de gêneros de vida — da relação entre o homem e a natureza e entre os homens, num processo de apropriação social da natureza, de longa duração com o concurso da noção de divisão social do trabalho, no centro do debate sobre o desenvolvimento das atividades produtivas, e sua organização espacial, significou uma importante mudança na literatura geográfica e em novas relações com a sociologia, num movimento - embora relutante, pois prevaleceria uma compreensão progressista do capitalismo - de reconhecimento das abstrações concretas, próprias do mundo moderno; da realidade das relações sociais formais, sintetizadas na alienação social do trabalho. Os desdobramentos teórico-metodológicos para a Geografia levam à centralidade, hoje, da categoria de produção do espaço.

O trajeto do conhecimento do objeto da Geografia Urbana, que se anuncia através dos estudos populacionais e se desdobra na repartição geográfica das cidades no mundo, com suas qualidades sócio-culturais, muitas vezes, de raízes de longa duração, definindo uma regionalização do fenômeno no mundo; esse trajeto, compreendido no plano mais abrangente do processo de conhecimento em geral, tem a profundidade do desenvolvimento do conhecimento moderno, assim como seus impasses: a relação dialética entre o infinito e o finito; entre a quantidade e a qualidade; entre a análise e a síntese; entre a parte e o todo, a superfície terrestre como um todo e a particularidade, mesmo a individualidade, dos lugares... ${ }^{5}$

Anunciemos então essas derivações, mesmo que esboçadas, em grandes linhas.

No trajeto do livro, que nos serve de base e exemplo, Geografia Urbana, de Pierre GEORGE, após essa aproximação do fenômeno urbano, através da população e seus índices, o autor discorre sobre a repartição das cidades no mundo. O importante a considerar, metodologicamente, é a contradição dialética quantidade-qualidade posta nesse movimento. Contradição que pode se resolver no livro, ao nível de seus conceitos mais evidentes, de modo formal; mas que é latente e de profundo resultado na definição do trajeto do desvendamento do objeto de estudo.

Se, nos primeiros capítulos, das duas partes do livro, a noção de quantidade funda a inteligibilidade do percurso, com a idéia do deciframento dos dados populacionais, os capítulos sobre a regionalização do fenômeno urbano trazem uma base qualitativa, que subverte o que veio antes. É a densidade dos modos de vida, das culturas, das técnicas e do trabalho humano, traduzida nas configurações geográficas. A natureza da análise altera seus procedimentos. Os documentos históricos passam à parte necessária do acervo de consulta. E a tragédia das mudanças urbanas e suas desigualdades vão sendo expostas.

Aqui um movimento importante no texto é aquele de introduzir os modernos processos econômicos e as configurações geográficas, resultantes e pressupostos dos mesmos processos — causa e efeito, na sua relação mútua. Assim, as repartições geográficas chegam à regionalização dos países desenvolvidos e subdesenvolvidos, como momentos necessários do moderno processo de desenvolvimento econômico.

Um momento demarcatório do livro base de nosso ensaio, referente à dialética entre quantidade e qualidade na Geografia Urbana, é a idéia do processo de urbanização que, no limite, inclui a noção de urbanização empírica, de extraordinária possibilidade, pois anuncia, nessa obra, a implosão-explosão da cidade como obra humana. ${ }^{6}$

Revista da ANPEGE. v. 5, 2009 
Assim, o eixo da compreensão do fenômeno urbano, como movimento da prática social — prática social, que poderíamos qualificar como alienada, inclusive da perspectiva do texto em exame - tem o processo de urbanização como base.

A base filosófica da repartição geográfica está assentada na enorme conquista da filosofia moderna que é o entendimento, a destruição do objeto para constituição de sua inteligibilidade 7 . Participa da negação da conquista da unidade, da totalidade como premissa metafísica escolástica ou mágica. A repartição geográfica das cidades no mundo, neste caso, comporta uma tradição de geografia comparada ${ }^{8}$, própria ao seu teor disciplinar, o que envolve dizer que à repartição acrescentam-se as noções de encadeamento, de relação de conjunto; os fenômenos particulares subordinando-se ao compito da "Terra tomada em seu conjunto".

Essa geografia comparativa tem como princípio uma geografia geral na relação com as particularidades, até singularidades, dos lugares. As monografias urbanas se compõem com estudos gerais e comparativos.

Neste livro, Pierre GEORGE, mesmo de modo não pensado plena e conceitualmente, exercita a metamorfose do espaço absoluto em espaço relativo. Ele se divide nesses dois pertencimentos da Geografia: a Geografia tradicional, antropológica, e a Geografia contemporânea, que deve conter uma concepção social da historicidade e da espacialidade modernas.

A noção de espaço absoluto, definido de modo materialista, confirma a não problematização da relação partes e todo; cada qual expressando o outro sem fissuras. Dessa maneira, a sociedade moderna, baseada na negação entre sujeito e predicado (em termos mais abstratos), não é suficiente e crucialmente expressa em suas contradições. Define-se assim o plano mental e, ao mesmo tempo, social, do espaço absoluto. Mentalmente, é o espaço geométrico e euclidiano; socialmente, é a sociedade moderna, o presente, sem contradições refletidas como tais; pelo menos, os fundamentos lógicos do pensamento geográfico não as esclarecem. Mas é exatamente Pierre GEORGE e seu grupo que em meados dos anos 1960 definem a idéia do espaço relativizado. O próprio espaço como situação. ${ }^{9}$

O debate sobre o espaço definido como absoluto, que aparece como fundamento lógico das concepções em curso, ao mesmo tempo, oferece a oportunidade de atualizar o livro e pô-lo em relação com Geografias Pós-modernas, de Edward SOJA, ambos nos levando a um percurso do pensamento em Geografia Urbana.

Como espaço absoluto, tudo se propõe como elemento e momento da organização do espaço. Nada se separa de modo estrito, isto é, nada é simplesmente decorativo. Organização aqui ganha o sentido do obedecer a uma 'ordem'. Não há o fortuito. A noção de superfície da terra prevalecerá e ela equivale a compor o mundo e sua repartição, excluindo o acima e o abaixo: o cosmos e as profundezas, a não ser quando estabelecem relações evidentes com essa superfície, quando técnica e socialmente passam a fazer parte da organização do espaço social. Às alturas, reserva-se a ciência da astronomia; da teologia... Às profundezas, à psicologia e mesmo à sociologia. Mas, as condições climáticas são parte da superfície; assim como, a geomorfologia absorve a geologia. E ambas podem configurar condições naturais a partir das quais o homem atua e definem segmentos da Geografia como ciência. A natureza humanizada, a produção de qualidades sócio-culturais e suas diferenças constroem a Geografia Humana, ou, especificamente, a Geografia Urbana, como civilizatória. A base é a natureza e a natureza modificada; o princípio da propriedade privada, no sentido lato, que se afirma como traço irrevogável do processo de modernização, vai aparecer por vezes como residual; ele posto, chega-se à noção de espaço relativo e não absoluto: envolvendo mediações abstratas, definidoras do espaço da acumulação. Na repartição geográfica das cidades no mundo, em sua regionalização, há um lugar proeminente para as qualidades sócio-culturais dos espaços; a realidade das abstrações concretas, econômicas, vai aparecendo a posteriori, não é o principio formador do argumento.

Revista da ANPEGE v. 5, 2009 
A argumentação aqui desenvolvida sobre a noção de espaço absoluto, no sentido concreto, materialista do termo, como fundamento dessa Geografia Urbana, não equivale a descaracterizá-la como anunciadora do que veio a ser a produção do espaço — incluindo o espaço como relacional ${ }^{10}$ —, mas se trata de demonstrar um movimento do conhecimento que é também, a partir do reconhecimento das diferenças e práticas sócio-espaciais, aquele da superação, mais o menos consciente, da natureza como base e princípio, enquanto superfície da terra, em prol do exame da "natureza abstrata" - a segunda natureza, produzida pelo homem e dele alienada -, exigida como fundamento do moderno. No plano fenomênico pode estar presente, na argumentação, o sentido último da modernidade, mas os instrumentos lógicos adequados ao seu conhecimento ainda havia que configurar. Isto é, no início, há um princípio homogeneizador, em relação e destrutivo das particularidades, e não as próprias particularidades regionais e locais a decifrar, depois o reconhecimento dessa abstração concreta.

O trabalho de Pierre GEORGE é o deste anunciador de uma geografia crítica.

Sim, o 2. ${ }^{\circ}$ capítulo do livro em exame é sobre origem e gênese das cidades; portanto, de suas particularidades. Nele, o autor identifica diferentes gerações de cidades no mundo, convergindo, no entanto, para tipos de cidades. Os tipos definem os modernos processos econômicos e sociais, atravessando as cidades, com histórias e passados diferentes e de modo diferente. Uma regionalização, como diz, em sentido lato, é o plano analítico; isto é: o conjunto urbano nos/dos países; as funções econômicas das cidades, definindo-as; e a distribuição das funções no interior de cada cidade. A composição desse capítulo com o 2. ${ }^{\circ}$ capítulo, da 2. ${ }^{a}$ parte do livro, sobre o trabalho urbano, nos ajuda a examinar sua atualidade conceitual.

Uma ruptura histórica, que move a transformação das cidades, costura toda a análise: a industrialização. Sendo que esta e seus derivados, como a extensão dos serviços e comércio — mais ou menos contraditórios - implicam em formas de trabalho concentrado, em fenômenos de massa, que metamorfoseiam as cidades. No interior de um raciocínio aparentemente desenvolvimentista, o autor formula uma tese crítica sobre o desenvolvimento das cidades: o crescimento das cidades conduz à negação (impossibilidade) do urbanismo (enquanto projeto coletivo, social) e está sob o privilégio da economia (indústria, finanças, circulação e especulação) e da arquitetura (como solução individual, isolada).

As cidades, como fenômenos de longa duração, remetem a um plano histórico contínuo, a partir do qual se localiza uma descontinuidade, que redefine esse complexo têmporo-espacial. ${ }^{11}$

Com instrumentos conceituais ainda ambíguos, preservando uma idéia de organicidade da cidade, o autor anuncia, num movimento logicamente não explicitado como contraditório: os limites do urbano na sociedade capitalista moderna. Assaltando o autor, para fundamentar sua atualidade, podemos devia-lo de algumas maneiras, como estamos tentando fazer até aqui. Será preciso ousar mais, no desvio, a seguir. Sendo o desvio a prática de utilizar o autor de modo irreverente, não para vulgarizá-lo ou enaltecê-lo, mas para posicioná-lo num outro patamar de relação, neste caso, com o conhecimento geográfico vindouro.12

A composição desviada entre os 3 . $^{\circ}$ capítulos, das partes 1 e 2 do livro em exame, nos permite um tratamento inusitado: partir das condições naturais, que enraizaram as cidades, cujo elemento analítico mais evidente é o sítio urbano, em escala local, para circunscrever esta escala, superando-a, na relação com outras escalas, como a regional. Assim, o par paradigmático dos estudos urbanos em Geografia remete ao sitio e à situação da cidade; par que propõe a concepção do urbano como relativa a diferentes escalas: no tempo e no espaço. No tempo, o sítio vai se desatualizando, as condicionantes naturais vão perdendo valor explicativo na explicação da morfologia da cidade; contudo, a análise remete aos inícios de formação do núcleo urbano, numa escala espacial local e à história de seu desenvolvimento morfológico. A situação define um segmento regional de tratamento da cidade, seu processo de irradiação, e garante, o tempo todo, o exame da atualidade das condições materiais de relacionamento da cidade com o

Revista da ANPEGE. v. 5, 2009 
entorno; as condições de desenvolvimento urbano, no âmbito da organização dos meios de transporte, de circulação e troca. Neste sentido, o problema fundamental da geografia urbana é o problema da geografia da circulação, envolvendo o deslocamento de homens e mercadorias em quantidades de crescimento exponencial. A geografia urbana reitera-se por sua natureza de fenômeno de massa. Sob impulsos naturais particulares, a posição da cidade recebe os meios de comunicação sempre renovados e acrescentados. A concepção, então, à base dessas transformações, é a formação de um sistema de organização territorial, como fator decisivo. A escala geográfica é a regional, no sentido lato, inclusive, quanto à situação e na escala temporal conta a atualidade das conquistas técnicas e científicas, que move as novas condições materiais de circulação em geral. Esta geografia, que vai se forjando, no urbano,

- sobre a revolução industrial no urbano, no âmbito planetário tem-se: cidade nova (criação da industrialização); cidade, com passado, transformada (pela industrialização); e cidade tradicional (ecos da transformação);

- como características do movimento urbano: sociedade rural (cidade e conjunto patriarcal); coexistência de arcaísmos e modernismos (duas cidades); e sociedade urbana (separação entre as atividades produtivas e as atividades residenciais - incluindo a utopia dos pavilhões e os movimentos diários da população ativa), incluindo a idéia de conurbações industriais.

A Urbanização Crítica na Metrópole de São Paulo é a geografia como geografia da circulação, inclusive, do ponto de vista da vida cotidiana: a noção de ambiente equivale a conceber como as formas de organização da vida material interferem na vida cotidiana. A circulação necessária de grandes massas de população, diariamente. A mobilidade da população urbana localiza um temário caro aos estudiosos do cotidiano, temário que aparece nessa obra: o tempo obrigatório, a imposição de uma penosa circulação diária ou impossibilidade de.

Do par sitio e situação não extraímos, somente, um darwinismo da formulação em geografia urbana, mas também a atualidade de seu tratamento da cotidianidade (cuja formulação teórica apenas de esboça). Para uma leitura mais vulgarizada, a estrutura analítica de apoio, desse livro, neste momento, reiterada em compêndios de geografia urbana, faz prevalecer à arquitetura dos condicionamentos naturais.

Contudo, temos como movimento de superação dos condicionamentos naturais um sentido que não se define como ascendente, no limite último: condições naturais; sistema de organização territorial e ambiente e vida cotidiana.

Através do trajeto exposto mais acima, de Pierre GEORGE, que vai de condicionantes naturais ao sistema territorial organizado e dele ao ambiente subversivo à vida cotidiana dos citadinos, como modo de deterioração da vida urbana, temos um trajeto anunciado que não cabe em esclarecimentos sobre se é positivista ou não o argumento do autor, mas que o mesmo, com instrumentos conceituais não suficientes, chega a considerar a alienação social, através do urbano.

No capítulo terceiro, "Aspectos da vida social urbana", da segunda parte do livro Geografia Urbana, Pierre GEORGE anuncia, sintética e conceitualmente, a tese do texto, da qual derivará sua estrutura analítica em fases da vida na e da cidade: "mobilidade cotidiana da população, recurso aos equipamentos comerciais, aos serviços de todos os tipos, busca de lazer e de descanso". Que, na condição de fenômeno de massa, comporta situações de vida provisórias e instáveis. É próprio da condição citadina, em sociedades industriais, esta vulnerabilidade social.

O composto atividades produtivas - movidas pelo processo industrial - e vida cotidiana na cidade é explosivo, redefinindo os limites do fenômeno urbano. As formas de irradiação para além da cidade levam à consideração das redes urbanas, das formas de conurbação, da constituição de periferias. $\mathrm{O}$ quadro tradicional da cidade é rompido, e ela é, ao nível da vida cotidiana, penosamente suportada.

Revista da ANPEGE v. 5, 2009 
"Este esquema geral deve ser retocado em função do desigual desenvolvimento econômico e social dos diversos países e também de certas modalidades da organização da vida coletiva."13

O plano da análise dos últimos capítulos (4. ${ }^{\circ}$ e $5 .^{\circ}$ da $1 .^{a}$ parte e último da $2 .^{a}$ parte), sinteticamente, pode ser reconduzido a partir da idéia de espaço de catástrofes..$^{14}$

A organização do espaço urbano, redefinida e cada vez mais funcional, inserida na dinâmica abstrata da economia moderna, que materialmente se transforma exponencialmente ${ }^{15}$, pode comportar a análise dos pontos de ruptura, dos pontos críticos da estruturação em curso. $\mathrm{O}$ argumento não flui somente no sentido da coerência e do equilíbrio das novas realidades urbanas, mas contém contradições não pensadas como tais, expostas como realidades sociais a corrigir, no âmbito coletivo estatista. O sentido dessa realidade urbana, como elemento crucial das contradições sociais modernas, não foi totalmente desvendado, mas o texto inclui momentos fundantes dessa possibilidade.

Da urbanização difusa à urbanização empírica, há a exposição do espaço de catástrofe do organismo urbano, como forma de agrupamento e forma de atividade: a explosão das cidades em periferias enquanto unidades urbanas incompletas. "A realidade é o aglomerado urbano. A cidade não é senão uma fração, o fenômeno é uma bola de neve"; sob pressão dos negócios financeiros, há expansão, com expulsão da maior parte da população dos núcleos citadinos e metropolitanos centrais.

Qual a passagem dessa geografia que viemos de explorar de alguma forma e aquela que veio a ser a geografia contemporânea crítica. Qual acervo as diferencia? Como? Profundamente? Superficialmente? Ao nível da história do pensamento geográfico, houve uma ruptura nítida entre o que foi a Geografia e o que veio a ser a Geografia Crítica. Para os anglo-americanos, a Geografia Radical. ${ }^{16}$

Aqui, indicamos a dificuldade de demarcar a ruptura, como descontinuidade absoluta. O movimento de superação da geografia anterior em relação à geografia contemporânea crítica está no seu fundamento marxista: a crítica à economia política.

Geografias Pós-modernas de Edward SOJA ${ }^{17}$, discutindo a dialética do espaço, de modo mais abstrato; localizando seu sentido na literatura marxista, seu ponto de ruptura com a dialética do tempo, esta última monopolizando essa mesma literatura, ao decifrar os fundamentos do capitalismo; e sintetizando o argumento, através de um ensaio paradigmático sobre Los Angeles, pode nos sugerir, como exercício metodológico, outros instrumentos conceituais e formais de interpretação geográfica; uma descontinuidade do pensamento em Geografia Urbana. Agora, essa descontinuidade pode se apresentar, com este e outros autores contemporâneos, sem se forjar na negação estrita do que foi antes a Geografia Urbana.

A Geografia que viemos de discutir, anteriormente, é elucidativa da grandeza do processo social de modernização, que atinge a todos, mesmo os lugares mais afastados de sua centralidade; embora, tal processo seja, inerentemente, desigual. Mesmo a expressão descritiva dessa presença, assim, aponta, incluindo a metamorfose ou dura destruição de tradições e culturas passadas. Uma Geografia Geral, que comportava a diversidade do fenômeno geográfico no mundo, definiu-se como momento necessário do projeto de Geografia Humana; neste caso tratado, realizando-se como Geografia Urbana.

Anuncia-se o capitalismo financeiro: incluindo a descrição de empreendimentos econômicos e especulativos envolvidos; varrendo as histórias de povos colonizados; reproduzindo-se em impérios; e constituindo uma massa de população potencialmente trabalhadora, agigantada e concentrada, especialmente, em grandes cidades. Perversamente, concentradas, pois são denunciadas as formas de segregação espacial produzida.

O pensamento marxista, cada vez mais interferindo na geografia produzida, acabou por produzir uma nova hipótese teórico-metodológica para a Geografia, ainda em constituição: a Geografia deixa de ser periférica no interior de uma teoria social crítica, e passa a lhe ser constitutiva.

Revista da ANPEGE. v. 5, 2009 
Na obra de SOJA aparece a idéia da importância do desenvolvimento geográfico desigual, na interpretação marxista do mundo. Ele teria o estatuto das contradições de classe na explicação do capitalismo, da relação capital-trabalho. Por esse caminho, o autor chega à necessidade de uma concepção dialética do espaço.

Na obra de SOJA, Geografias Pós-modernas, é possível compreender a centralidade do pensamento de Henri LEFEBVRE, que teria precipitado uma costura de tendências, que se afirmavam dentro e em torno do marxismo, com certa dificuldade, a propósito de uma dialética espacial e seu sentido na teoria social crítica. Do ponto de vista abstrato-conceitual, a noção de heterotopias, de FOUCAULT, punha outro registro do espacial na interpretação do mundo moderno, embora o autor, também, a tenha identificado como constitutiva de outras sociedades, ao longo do tempo histórico. "A heterotopia é capaz de superpor num único lugar real diversos espaços, diversos locais que em si são incompatíveis..."18. O espaço heterotópico é um espaço de contradição latente. Simultaneamente, realizam-se espaços diferenciais, exatamente invertidos, e, ao mesmo tempo, combinados. Do ponto de vista histórico-concreto, a concepção de MANDEL sobre a significância do desenvolvimento desigual, no processo capitalista ${ }^{19}$, juntamente com toda a obra sobre o Imperialismo, especialmente a de LENIN, esclarecem a tensão dialética entre diferenciação e igualação, própria das leis do movimento do capital, pondo as desigualdades geográficas no centro da explicação sobre a reprodução capitalista.

Do abstrato ao concreto, as visões sobre a espacialidade acabavam por desaguar, sintetizadas, nas concepções de LEFEBVRE sobre a relação entre produção social do espaço e reprodução social das relações de produção, expondo a necessidade de um pensamento, que incluísse a dialética do espaço.

$\mathrm{O}$ argumento de SOJA sobre a geografia humana crítica leva-o a refletir a geografia urbana através das reestruturações urbanas, como constitutivas do processo crítico do capital.

A economia política da reestruturação urbana e regional, que SOJA analisa a partir de Los Angeles, demarca a dialética do imóvel-móvel, arranjos espaciais urbanos provisórios, isto é, passíveis de destruições econômicas criadoras, produtiva e financeiramente compensatórias, próprias da economia contemporânea. O ponto de ruptura da imobilidade envolve uma rede complexa de produção de lugares. A direção de uma dialética do espaço expõe um movimento que vai da dialética do tempo àquela do espaço, tendo como intermediário, a ser negado, a fetichização do espaço; movimento necessário à compreensão crítica das forças estruturais do capitalismo.

A atualização da metrópole urbana ao nível da produção do espaço, explicitando a urbanização crítica

O que rege estas considerações é a tese de que há necessidade de uma leitura de totalidade da metrópole para expor sua inserção no processo social moderno, no compasso das estratégias econômicas e políticas de sua mercantilização. Para tanto, sustenta o argumento três complexos analíticos, sendo que cada um deles contém sintética e dialeticamente elementos com nexos contraditórios e em estreita conexão com os demais complexos. São eles:

1 - A crise do trabalho, contida na crise do capital. Esta crise se manifesta como desemprego maciço; aumento da composição orgânica do capital dos empreendimentos econômicos, que reduz proporcionalmente o trabalho vivo da referida composição; uma economia de "sobrevivência", em novos moldes, pois, diante da crise do trabalho, setores produtivos e de serviços, de baixa composição orgânica do capital, são mantidos e, pulverizadamente, $\operatorname{ampliados}^{20}$. Lembrando que a economia brasileira sempre conteve essa presença; daí todas as formas de dualismos a explicando: a formalidade e a informalidade do trabalho; mais recentemente, a exclusão e inclusão produtivas dos trabalhadores...

"Todo tempo de trabalho é tempo de produção" coincide com a análise da dissociação entre rendimento (proletário) e trabalho (produtivo na fábrica). Isto é: "desta leitura, decorre, na ordem do dia, a crise do trabalho - a atual fase histórica sendo marcada pelo fim do trabalho como centro de gravidade da 
vida e fundamento do laço social. Sobre o terreno da ação coletiva, esta crítica equivale a colocar uma dissociação entre rendimento e trabalho [... $]^{\prime 21}$

No interior dessa situação, de fundamento crítico, de modo pulverizado, no sentido de que em todo e qualquer espaço e em todo e qualquer tempo, são buscadas formas de sobrevivência, que incluem além de modos precarizados de trabalho, formas de assistência institucionalizadas (bolsa família, programa de renda mínima...). O Programa Fome Zero é bem ilustrativo da via estrutural em curso, nos países periféricos do capitalismo. É interessante notar que as grandes metrópoles constituem espaço-temporalmente essa presença do trabalho em tempo integral, completamente desvalorizado.

2 - As cidades passam a constituir espaços privilegiados da produção mercantil do espaço, internalizando a metamorfose do capital produtivo em capital financeiro. Não são espaços do homem-habitante como, por algum tempo, definia LE LANNOU, nem, exatamente, espaços do homem-produtor e do homem-consumidor, como avaliava Pierre GEORGE, para citar autor já mencionado, mas espaços do habitat e dos negócios, que negam o homem; espaços de desumanização e sujeição social e individual. De modo fenomênico, as cidades tornam-se sujeitos sociais ${ }^{22}$; em sua essencialidade, é o processo de urbanização, tendo como fundamento a proletarização absoluta. Deslocar o sujeito na direção do processo de urbanização significa que todos os espaços e tempos sociais são absorvidos, tendencialmente, pelo processo do capital. $\mathrm{O}$ espaço como um todo move-se, economicamente, segundo as necessidades da economia urbana, voraz, inteiramente baseada na urbanização como negócio. Sob esse fundamento, não há como identificar um sujeito, senão aquele imanente à própria economia desumanizadora. Não há um sujeito e seu habitat, como moradia degradada; há o habitat, negando o habitante, no interior de uma economia, que nega, contraditoriamente, o trabalho. Dialeticamente, aparecem como necessidade de moradia e necessidade de trabalho. Dizer que o habitar se transforma em habitat, significa dizer que o habitante não é o sujeito, mas o negócio imobiliário o é, e todas as suas extensões econômico-políticas. Dizer que há negação do trabalho é dizer que existe uma economia que se move, contraditoriamente, por destituição do trabalho e tornando todo tempo humano um tempo de todo e qualquer trabalho. Ela sujeita e é o sujeito. No fundo, são alienações por destituição de apropriações sociais e individuais possíveis. O desenvolvimento das forças produtivas sociais, absorvidas pelo capital, cada vez mais financeirizado, se resolve socialmente, inclusive, comportando restos de técnicas, inseridos na vida cotidiana urbana. Nas imensas periferias, a dos centros histórico e expandido das cidades, ou a do seu entorno, cada vez mais amplo e distanciado, metropolitano, prevalece a baixa composição orgânica do espaço, que aparece como falta de infra-estrutura urbana. Designamos por urbanização crítica. O movimento é ir distanciando os espaços periféricos e ir constituindo novas centralidades econômicas metropolitanas. ${ }^{23}$

O planejamento espacial faz parte constitutiva das estratégias político-econômicas.

O "trabalho intelectual" se resolve na realização superestrutural de uma pesada carga legal, de escalas multiplicadas e sobrepostas - leis regionais, municipais e federais; combinadas com regulamentos setoriais - numa enorme burocratização, incluindo além do aparelho estatal, organizações não governamentais, com vistas a assegurar o enobrecimento dos espaços degradados socialmente, incluindo justificativas sociais, para o que acaba se realizando, especialmente, como uma economia urbana ou produção do espaço urbano. No interior dessa superestrutura, há conquistas sociais, proporcionalmente, bem inferiores à economia em movimento.

A lei, n. ${ }^{\circ}$ 10.257, referente ao Estatuto da Cidade, regulamentada em 2001, significa, contraditoriamente, uma modernização do aparato legal com vistas ao direito de propriedade. Do ponto de vista das Operações Urbanas, equivale à manipulação dos índices e características de uso e ocupação do solo e a 
um processo de financeirização da propriedade privada da terra urbana ${ }^{24}$. E, ao mesmo tempo, institui a função social da propriedade, como combate à especulação urbana, servindo de justificativa política para as ocupações urbanas, realizadas por movimentos sociais urbanos, reiterada e violentamente combatidas, através de instituições do Estado; reprimidas como invasões de propriedade alheia.

Os conteúdos da necessária dialetização do espaço envolvem: o aparato legal de apoio, sustentado por uma leitura estratégica do espaço, apoiada em lógicas espaciais que arrematam e sintetizam mecanismos econômicos e políticos, neste caso, metropolitanos; seu desdobramento financeiro e social, pois se estabelece que a economia urbana vai tecendo um processo de reprodução do capital imobiliário, inclusivo de sua financeirização, produtor do habitat e dos negócios, no seio da produção do espaço urbano, portanto, definindo formas de sujeição social. No caso de São Paulo, a composição ou o conjunto das Operações Urbanas Consorciadas, do Plano Diretor Estratégico do Município, projetadas e existentes, revela-se claramente como espaço instrumental, instruindo os mecanismos econômicos e financeiros.

A mobilização da propriedade privada da terra, no interior da produção do espaço urbano, tem um desdobramento de 2. ${ }^{\circ}$ grau: além de colar num segmento produtivo como o do capital imobiliário, e inclusive através dele, reproduz-se na sua financeirização e na implicação de instituições do Estado, diretamente, na manipulação do agenciamento financeiro ${ }^{25}$. Como processo de urbanização, configura-se um circuito próprio de capital imobiliário, com suas conseqüências tanto no processo do capital, como nos limites da vida urbana; o que se observa, hoje, como imediatamente materializado. E esse circuito deixa de ser secundário no conjunto dos setores econômicos. Negativamente, define-se uma acumulação primitiva do espaço: um processo de expropriação, combinado à degradação do trabalho, antes enunciada.

A produção de uma nova centralidade é, imediata e sensivelmente, a expropriação dos usos anteriores desse mesmo lugar. Com SMITH, poderíamos falar de produção de escalas geográficas: produz-se uma centralidade e, ao mesmo tempo, sua periferia, incluídos no mesmo processo. 26

No caso de São Paulo, as estratégias imobiliárias renovadas sugerem a direção sudoeste, preferencialmente. Estratégias que se expandem, também, por outros eixos de valorização, o que nos leva ao Rodoanel (grande anel viário metropolitano perimetral), como a fronteira desenhada dos novos negócios potenciais da urbanização.

Sob o ponto de vista da urbanização crítica, é possível examinar a produção do espaço num processo de continuidade-descontinuidade da produção industrial na moderna sociedade capitalista: determinados setores produtivos ganham potência entre os negócios — as indústrias da construção, que deixam de ser um setor secundário - ; desenvolve-se um sistema complexo de comercialização do produto-espaço — as incorporadoras e imobiliárias internacionalizadas e consorciadas no urbano a ponto de produzir territórios de negócios - ; a circulação da riqueza produzida e fictícia envolve um processo ampliado de financeirização; políticas diversas amparam a pulsação das necessidades dessa produção; e a produção do espaço atualiza a importância da mobilização da moderna propriedade da terra — aqui também se vai de extração de rendas da terra urbana, a partir de estratégias econômicas e urbanas, a rentismos vários, na rabeira das tais estratégias de negócios urbanos. Pode-se falar de uma estratificação espacial das centralidades: de centralidades locais - que facilitam a vida cotidiana da população em sua mobilidade diária e oferecem os serviços e comércio básicos —; às regionais (na mesma zona da metrópole) — que incluem as redes comerciais e de serviços de maior porte —; às metropolitanas — cujo acesso é mais reduzido, e que podem incluir uma inserção profissional necessária à sobrevivência —; e assim por diante.

Por esse caráter, o da densidade relativa da composição orgânica do espaço, como momento necessário de elucidar a urbanização crítica, insistimos na dialética centro-periferia27. Ao mesmo tempo tem-se a 
produção de novas centralidades, que conduzem à mobilidade espacial da população originária do lugar e a empurra para a fronteira dessa nova nucleação.

3 - Esta profunda destituição da humanidade do homem é, ao mesmo tempo, a "naturalização" do humano. SCALZONE diz "A crítica ecológica compreendeu na raiz uma das questões centrais de nossa época: a relação entre modernização e catástrofe." 28

Há uma exaltação da natureza e do natural, preenchendo o vazio de projetos políticos de superação de inúmeras crises sociais. A potência ideológica do ambiental, substituindo o "caos sócio-espacial" é extremamente paradoxal, pois, em São Paulo, chega a ser justificativa do Rodoanel Mário Covas, um projeto setorial da área de transportes, definindo um sistema viário perimetral, que circunda a metrópole de São Paulo, na altura do que é designado por anel peri-urbano; dividido em 4 trechos, sendo que o Trecho Oeste já está em funcionamento (desde 2002) e o Trecho Sul está em produção; nesses dois trechos, já são $90 \mathrm{kms}$ de estrada previstos. Faltam os trechos Norte e Leste, fechando o circuito de por volta de $175 \mathrm{kms}$, distantes de 20 a 40 kms do centro histórico de São Paulo; sendo que o Trecho Sul já precipita uma ligação possível com o que se constituirá como Trecho Leste, e assim sucessivamente. Novamente, prevalece uma noção de conjunto da área metropolitana a irrigar, economicamente.

Para justificar uma rodovia assim extensa e seu sentido, na base de uma nova plataforma logística para os negócios metropolitanos, ela aparece induzindo o chamado efeito barreira, "inibidor da ocupação irregular" 29 e do avanço do que foi convencionado como urbanização desordenada ${ }^{30}$ — ocupações irregulares, do ponto de vista fundiário e urbanístico: favelas e loteamentos clandestinos, a maioria que denota o que se definiu como anel peri-urbano. E exatamente o sistema rodoviário em implantação se apresenta como um elemento propulsor da qualidade ambiental de espaços metropolitanos; estes já definidos como áreas de conservação e proteção ambiental (especialmente, nas zonas sul, sudoeste e norte da metrópole), com uma normatização, datada dos anos 1970, que foi sucumbindo aos fracassos sucessivos dos avanços da urbanização metropolitana e, repetidamente, reformulada no plano legal.

As leis de proteção ambiental indicam a magnitude da periferia urbana envolvida e por conta disso sofrem inúmeras modificações, absorvendo e revelando, através dessas modificações, as próprias dificuldades de sua realização. Ainda mais, elas mesmas justificam o crescimento do mercado popular de terras, em certas áreas protegidas, que passam, com essas leis, a serem desvalorizadas para outros usos; caso de parte substantiva da Zona Sul de São Paulo. ${ }^{31}$

O motor econômico de enobrecimento desses espaços peri-urbanos, através de novos condomínios, projetos econômicos e atualização da infra-estrutura urbana, combina-se com a ideologia da preservação e conservação ambientais. Retira-se o inconveniente de milhões de gente, aí fixados, restando a combinação entre economia e natureza. A primeira como base estrutural; a segunda, sua superestrutura ideológica de suporte. Mesmo que, paradoxalmente, justificando uma rodovia expressa e suas extensões viárias.

O espaço instrumental, assim conceituado, por Henri LEFEBVRE, na metrópole de São Paulo serve para configurar uma substituição crucial: a neutralização do social por meio da natureza-natural.

O Rodoanel Mário Covas, como sistema viário perimetral, projetado e em execução, desde os anos 1990, atravessa a metrópole de São Paulo ${ }^{32}$ e passa a demarcar o círculo e circuito de realização e renovação potenciais de valorização econômica desta metrópole ${ }^{33}$. Ele nos fornece a imagem do perímetro urbano metropolitano que foi desenhado e está se implementando, formando um grande anel de valorização econômica do espaço. Ele determina um contexto e uma imagem espaciais de totalidade sobre a produção do espaço urbano e, imediatamente, ele alavanca um processo de expropriação social, próprio à acumulação primitiva do espaço, que forja o espaço de valorização. 
Uma noção de conjunto da "realidade urbana economizada" torna-se mais patente se preenchermos essa imagem totalizante do Rodoanel Mário Covas com outros projetos, como aqueles das Operações Urbanas em São Paulo.

O Programa Rodoanel Mário Covas pode estar definindo a magnitude necessária das políticas urbanas, com vistas a mobilizar economicamente as imensas periferias metropolitanas. Tal Programa apresenta-se como política econômica sustentável, corrigindo a "péssima qualidade ambiental das áreas periféricas pobres".

A urbanização, definida crítica, cujo fundamento subjetivo negado é a massa proletária das periferias metropolitanas, sujeita aos avanços do capital imobiliário, e de outras formas de capital, financeirizadas, e sob incentivo estatista, inclui a produção de representação em telescopagem34, entre a crise social e a crise ambiental, a partir de políticas de sustentabilidade, como imagética ilusória de equilíbrio.

As maneiras como a impossibilidade do urbano aparece põem desequilíbrios constitutivos: nos conjuntos habitacionais e em outras formas de loteamentos urbanos, os adensamentos, que compro $\neg$ metem a urbanização dos mesmos; o controle dos que poderão fazer parte dos mutirões para torná-los viáveis; o receio das invasões, numa ocupação; o embate entre as questões sociais e aquelas especificamente ambientais; tornar o lugar mais urbano significa, nos limites desta reprodução social crítica, expulsar a população que é excedente; e dependendo de seus termos, esta seleção é quase naturalizada.

É possível permanecer na telescopagem dos problemas ambientais e sociais? Seria possível administrálos? Seria possível neutralizar a centralidade do econômico na sociedade moderna?

É possível compreender a revisão econômica do território metropolitano urbano, atualizando a metrópole de São Paulo, para os novos negócios urbanos. Ela deve ganhar uma macro-dimensão para mover uma área extensa de usos residenciais populares e dar lugar a novos investimentos. As polêmicas, entre os últimos prefeitos, a partir do final dos anos 1980, demonstram como essas novas estratégias estatistas, configurando o território economizado da metrópole, ainda estão em curso e definição.

Alguns elementos, do que foi tratado, visam ser uma representação analítica do urbano economizado como totalização, e dos restos que sobram à massa proletária. Não são fatos, são processos; estão em curso e se realizarão mais ou menos, no tempo e no espaço, segundo a eficácia das formas de atualização da metrópole de São Paulo, na tentativa de inserção na circulação global dos negócios que movem o mundo. E depende do lugar no mundo economizado, dessa porção que é a metrópole de São Paulo. É uma escala produzida e em produção, que depende das outras, internacionalizadas, para se realizar de fato. Diríamos, está em preparação o terreno para essa possibilidade, nos termos da produção social do espaço, e a extensão da crise social, que precipita.

\section{NOTAS}

(1) GEORGE, Pierre. Geografia urbana. São Paulo: Difel,1983. (no original, Précis de Géographie Urbaine).

(2) Data de 1952, o livro "La Ville, le fait urbain à travers le monde", do autor. E, em 1961, lança "Précis de géographie urbaine", no qual nos baseamos. Revista da ANPEGE, v. 5, p. 51 - 70, 200951

(3) HEGEL, Morceaux Choisis. Paris: Gallimard, 1995 (primeira edição 1939), p. 163 (Propedêutica Filosófica). Tradução de Henri Lefebvre e Norbert Guterman.

(4) GEORGE, Pierre. Geografia Urbana, 1983, p. 165.

(5) O objeto da Geografia, contendo a relação entre o homem e a natureza e entre os homens, contém a infinitude do que é essencial da natureza; da relação entre o homem e a natureza; e entre os homens; e de suas relações mú- 
tuas. Mas, ao mesmo tempo, deve se realizar como finitude e o faz elegendo a superfície da terra como totalidade. Sempre lembrando a plasticidade dessa base material e finita: o ecúmeno, em constante acréscimo; inclusive, com o desenvolvimento científico e técnico. Há uma contradição dialética implicada no objeto: a relação entre infinito e finito. O importante a considerar é que a contradição existe, mas pode não estar explicitada, pensada, resolvida, enquanto dialética, pela Geografia.

(6) Fartamente discutida por Henri LEFEBVRE; entre as citações, destacamos Le droit à la ville suivi de Espace et politique. Paris: Anthropos, 1974 e La Révolution Urbaine. Paris: Gallimard, 1970.

(7) LEFEBVRE, Henri. Descartes. Paris: Éditions Hier et Aujourd'hui, 1947. Excelente análise da filosofia moderna, em concepção, no século XVII.

(8) À Geografia se reservaria o tratamento das diferenças localizadas na superfície da terra, comparando-as. (CAPEL, Horacio. Filosofía y Ciencia en La Geografía Contemporánea. Barcelona: Barcanova, 1981, p. 321)

(9) GEORGE, Pierre; GUGLIEMO, Raymond; LACOSTE, Yves e KAYSER, Bernard. A Geografia Ativa. São Paulo: Difusão Européia do Livro/EDUSP, 1966.

(10) “Devemos, também, pensar relacionalmente o espaço porque há um sentido importante no qual um ponto no espaço 'contém' todos os outros pontos [...] e é também crucial para entender a determinação do valor do solo..." (HARVEY, David. A justiça social e a cidade. São Paulo: Hucitec, 1980, p. 143-144)

(11) Algumas tentativas para demonstrar a extensão e intensidade das mudanças são assim expressas:

(12) Sobre a noção de desvio, Internationale Situationniste. Paris: Fayard, 1997.

(13) GEORGE, Pierre. Geografia Urbana, 1983, p. 203.

(14) OSEKI, Jorge Hajime. O único e o homogêneo na produção do espaço. IN: MARTINS, José de Souza (org.) Henri Lefebvre e o retorno à dialética, 1996, p. 109-119.

(15) É, inclusive, belo e dramático o texto sobre Tunis, cidade colonizada pelos franceses, representativa do que veio a ser outras cidades do Norte da África. (GEORGE, Pierre. Geografia Urbana, 1983, p. 129-132)

(16) JOHNSTON, R. J. Geografia e Geógrafos. São Paulo: Difel, 1986.

(17) SOJA, Edward. Geografias Pós-Modernas - A Reafirmação do Espaço na Teoria Social Crítica. Rio de Janeiro: Jorge Zahar, 1993.

(18) SOJA, Edward. Geografias Pós-modernas. Rio de Janeiro: Jorge Zahar, 1993, p. 24-30, citando Foucault, p. 25.

(19) “Ao não subordinar a estrutura espacial do desenvolvimento desigual à classe social, mas encará-la como estando 'no mesmo plano', Mandel identificou, na escala regional e internacional, uma problemática espacial que se assemelha de perto à interpretação da espacialidade urbana por Lefebvre, a ponto de sugerir, inclusive, uma poderosa força revolucionária emergindo das desigualdades espaciais, que ele claramente afirmou serem necessárias à acumulação capitalista.” (SOJA, Edward. Geografias Pós-modernas, 1993, p. 103)

(20) “A tendência à formalização das relações sociais estancou nos anos 1980, e expandiu-se o que ainda é impropriamente chamado trabalho informal [...] a desconstrução da relação salarial que se dá em todos os níveis e setores. Terceirização, precarização, flexibilização, desemprego a taxas de 20,6\% na Grande São Paulo - dados de 2003 [...] -, e não tão contraditoriamente como se pensa, ocupação, e não mais emprego [...]” (OLIVEIRA, Francisco de. Crítica à razão dualista / O ornitorrinco. São Paulo: Boitempo, 2003, p. 142). "Então, graças à produtividade do trabalho, desaparecem os tempos de não trabalho: todo o tempo de trabalho é tempo de produção." (Op. cit. p. 136, negrito nosso)

(21) MARTINI-SCALZONE, Lucia e SCALZONE, Oreste. Écologisme et autonomie. IN: GROUPE DE NAVARRENX. Du Contrat de Citoyenneté. Paris: Syllepse/Périscope, 1990, p. 226-227.

(22) Fala-se em protagonismo das cidades: "entre os itens de inserção: a promoção econômica para o exterior e a concepção e implementação de projetos urbanísticos. (BARRETO, Maria Inês. Inserção internacional de governos locais. IN: Revista Teoria e Debate. São Paulo: Fundação Perseu Abramo, ano 17, n. ${ }^{\circ}$ 59, agosto/setembro de 2004, 
p. 12). A concepção dos projetos urbanos tem por base o tratamento da cidade como empresa-cidade. (OSMONT, Annik. La banque mondiale et les villes — du développement à l'ajustement. Paris: Karthalam 1995, p. 281)

(23) Especialmente significativo sobre este trajeto, entre outros, de toda uma geração de novos geógrafos devotados ao tema é a pesquisa de Ana Fani Alessandri CARLOS. (CARLOS, Ana Fani Alessandri. Espaço-tempo na metrópole. São Paulo: Contexto, 2001)

(24) "Sob a forma de Operações Urbanas, os interessados em construir grandes edifícios que extrapolam o zoneamento 'normal' podem fazê-lo nas regiões delimitadas por esse instituto, bastando para isso a compra de 'aditivos' à propriedade que podem ser adquiridos da própria municipalidade, ou de particulares, vista serem direitos reais, representados por papéis de livre negociação. Com a raridade do espaço horizontal criou-se a raridade do espaço vertical, ainda que fictícia, sob a representação de títulos que na cidade de São Paulo chamam-se CEPACs (ou Certificados de Potencial Adicional de Construção), que são igualmente finitos, embora sejam apenas números." (BAITZ, Ricardo. A propriedade contra a posse e a propriedade 2. IN: GEOUSP - Espaço e Tempo. São Paulo: Departamento de Geografia, FFLCH, USP, 2007, n. ${ }^{\circ}$ 22, p. 95).

(25) Observem-se os CEPACs - certificados de potencial adicional de construção —, instrumentos financeiros ligado às Operações Urbanas, tornados títulos, alienados em leilões, vendidos no mercado, podendo ser, de modo fictício, valorizados. O que se pretendia era angariar fundos para os investimentos definidos como públicos, mas, na verdade, se alavancam os investimentos, em parceria, com o setor privado.

(26) SMITH, Neil. Geografia, diferencia y políticas de escala. IN: Terra Livre. São Paulo: AGB, ano 18, n. ${ }^{\circ} 19$, julho/dezembro de 2002 .

(27) “A noção de centro e de periferia é uma noção muito importante na condição de ser precisada e diferenciada." Sugere "sempre novas centralidades e novas periferias." É possível considerar a noção de centralidades subordinadas. (RENAUDIE, Serge (e outros). Henri Lefebvre - Uma nova positividade do urbano. Paris: Journal M, fevereiro de 1988, p. 62-66.

(28) MARTINI-SCALZONE, Lucia e SCALZONE, Oreste. Écologisme et autonomie. IN: GROUPE DE NAVARRENX. Du Contrat de Citoyenneté. Paris: Syllepse/Périscope, 1990, p. 228.

(29) Avaliação Ambiental Estratégica do Programa Rodoanel. São Paulo: Governo do Estado de São Paulo, 2004.

(30) A concepção de urbanização desordenada, que induz à idéia de planificação, contradiz àquela de urbanização crítica.

(31) A propósito dos loteamentos da Represa Guarapiranga, pesquisas recentes sugerem um mercado informal de terras muito lucrativo, impulsionado pela própria legislação ambiental. O mesmo se repete na Billings.

(32) O Projeto Rodoanel Mário Covas refere-se a um anel rodoviário metropolitano fechado, cortando as principais rodovias de acesso à metrópole, cuja produção é controlada pelo governo do Estado de São Paulo e pelo governo federal. O primeiro trecho, oeste, interliga a rodovia Régis Bittencourt com a estrada velha de Campinas, em Perus, passando pelas rodovias Anhanguera, Bandeirantes, Castelo Branco e Raposo Tavares, com 32 kms. Ele está concluído. O segundo trecho, sul, vai ligar a rodovia Régis Bittencourt com a rodovia Anchieta (passando pela rodovia Imigrantes), tendo por volta de $40 \mathrm{kms}$. Completam o circuito os trechos norte e leste. O rodoanel metropolitano envolve, além de São Paulo, mais 15 municípios. No trecho oeste, estão Barueri, Carapicuíba, Cotia, Embu e Osasco. No sul, Embu, Itapecerica da Serra e São Bernardo do Campo. No leste, Mauá, Ribeirão Pires, São Bernardo, Ferraz de Vasconcelos, Itaquaquecetuba, Guarulhos, Poá e Suzano. No norte, Guarulhos.

(33) Há uma metamorfose da funcionalidade da presença do trabalhador potencial na do morador temporário. A valorização e capitalização das periferias, inclusive reproduzindo formas de especulação financeira e fundiária, constitutivas de centralidades potenciais, acabam por levar a uma acumulação primitiva desses espaços; isto é, uma varredura dos seus usos e moradores existentes, em prol de novas estratégias e empreendimentos. Considerando a imensidão das periferias, as estratégias de expropriação devem ser gigantescas, a exemplo do Rodoanel Mário Covas, em São Paulo, que envolve potencialmente a metrópole inteira. 
(34) O termo foi configurado por Henri Lefebvre. A télescopage está no plano da produção de uma ilusão, de uma confusão, de um misto de realidade e representação, potencializado, por transferência e redefinição de conteúdos, terrivelmente ativas. LEFEBVRE, Henri. Production de 1'Espace. Paris: Anthropos, 2000, 4. a edição.

\section{REFERÊNCIAS BIBLIOGRÁFICAS}

BAITZ, Ricardo. A propriedade contra a posse e a propriedade 2. GEOUSP - Espaço e Tempo. São Paulo: Departamento de Geografia, FFLCH, USP, 2007, n. ${ }^{\circ} 22$.

BARRETO, Maria Inês. Inserção internacional de governos locais. Revista Teoria e Debate. São Paulo: Fundação Perseu Abramo, ano 17, n. ${ }^{\circ}$ 59, agosto/setembro de 2004.

CAPEL, Horacio. Filosofía y Ciencia en La Geografía Contemporánea. Barcelona: Barcanova, 1981.

CARLOS, Ana Fani Alessandri. Espaço-tempo na metrópole. São Paulo: Contexto, 2001.

GEORGE, Pierre. Geografia urbana. São Paulo: Difel,1983.

GEORGE, Pierre; GUGLIEMO, Raymond; LACOSTE, Yves e KAYSER, Bernard. A Geografia Ativa. São Paulo: Difusão Européia do Livro/EDUSP, 1966.

HARVEY, David. A justiça social e a cidade. São Paulo: Hucitec, 1980.

HEGEL, Morceaux Choisis. Paris: Gallimard, 1995.

JOHNSTON, R. J. Geografia e Geógrafos. São Paulo: Difel, 1986.

LEFEBVRE, Henri. Descartes. Paris: Éditions Hier et Aujourd'hui, 1947.

LEFEBVRE, Henri. Production de l'Espace. Paris: Anthropos, 2000, 4. a edição.

LEFEBVRE; Henri. La Révolution Urbaine. Paris: Gallimard, 1970.

LEFEBVRE; Henri. Le droit à la ville. Paris: Anthropos, 1974

MARTINI-SCALZONE, Lucia e SCALZONE, Oreste. Écologisme et autonomie. IN: GROUPE DE NAVARRENX. Du Contrat de Citoyenneté. Paris: Syllepse/Périscope, 1990.

OLIVEIRA, Francisco de. Crítica à razão dualista / O ornitorrinco. São Paulo: Boitempo, 2003.

OSEKI, Jorge Hajime. O único e o homogêneo na produção do espaço. IN: MARTINS, José de Souza (org.) Henri Lefebvre e o retorno à dialética, 1996, p. 109-119.

OSMONT, Annik. La banque mondiale et les villes — du développement à l'ajustement. Paris: Karthalam 1995. RENAUDIE, Serge (e outros). Henri Lefebvre - Uma nova positividade do urbano. Paris: Journal M, fevereiro de 1988, p. 62-66.

SMITH, Neil. Geografia, diferencia y políticas de escala.Terra Livre. São Paulo: AGB, ano 18, n. ${ }^{\circ}$ 19, julho/ dezembro de 2002.

SOJA, Edward. Geografias Pós-Modernas - A Reafirmação do Espaço na Teoria Social Crítica. Rio de Janeiro: Jorge Zahar, 1993.

Recebido em abril de 2009 Aceito em agosto de 2009 